\title{
O Uso Do TRANSLOG@ NAS PRIMEIRAS PRÁTICAS TRADUTÓRIAS
}

\section{The USE OF THE TRANSLOG IN THE FiRST TRANSLATION PRACTICES}

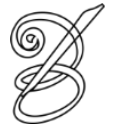 \\ Luciane Leipnitz ${ }^{\mathrm{i}}$ \\ (Professora Adjunta - CCHLA/UFPB - João Pessoa/Brasil) \\ luciane.leipnitz@gmail.com
}

\begin{abstract}
Resumo: Neste artigo relata-se a experiência do uso do Translog $2000 @$ na disciplina de Prática de Tradução de Textos Gerais no Curso de Bacharelado em Tradução da UFPB. O objetivo das atividades desenvolvidas em sala de aula de semestres iniciais do Curso foi despertar o aprendiz de tradução para uma reflexão sobre a sua prática, além de familiarizá-lo com diferentes aspectos que envolvem e influenciam o desenvolvimento da atividade. Os protocolos de registro de teclado gerados pelo Translog foram analisados pelos próprios aprendizes como ponto de partida para a reflexão sobre a busca por soluções na tradução, sobre a duração das pausas durante o processo, sobre as escolhas tradutórias. A partir dessas reflexões, os aprendizes produziram um relatório final com suas observações. Pretendeu-se oferecer aos aprendizes uma aproximação real à prática, conscientizando-os a respeito de seu processo tradutório, de modo a buscar o desenvolvimento de sua competência tradutória.

Palavras-chave: processo tradutório, aprendizagem reflexiva, competência tradutória.
\end{abstract}

Abstract: This article reports the experience of using the Translog 2000@ in the discipline Translation Practice of General Texts in the Translation undergraduate course from UFPB. The aim of the classroom activities developed in the first semesters of the course was to make the learners reflect on their translation practice, and to make them familiar with different aspects which surround and influence the accomplishment of the task. The keyboard's recording protocols - generated by the Translog - were analyzed by the learner as a starting point for reflection about the search for solutions in the translation, about the pause periods during the process, and also about the translation choices. Based on these reflections, the learners produced a final report with their observations. It was intended to provide the learners with a real practice experience, making them aware of their translation process in order for them to pursue the development of their translation competence.

Keywords: translation process, reflective learning, translation competence

\section{Introdução}

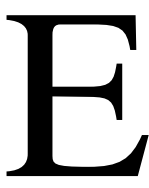
ste artigo apresenta um relato da experiência com o uso do software Translog 2000@ ${ }^{\text {ii }}$ em sala de aula na disciplina de Prática de Tradução de Textos Gerais do Curso de Bacharelado em Tradução da UFPB em João Pessoa, Paraíba, no período

2012.2.

O Curso de Bacharelado em Tradução da UFPB, criado em 2009, faz parte do Programa de Apoio ao Plano de Reestruturação e Expansão das Universidades Federais (REUNI) do Governo Federal, que tem como objetivo expandir as vagas para estudantes de graduação no sistema federal de ensino superior e dotar as universidades federais das condições necessárias para ampliação do acesso e da permanência na educação superior. O 
Curso tem como objetivo principal promover a formação do profissional tradutor, por meio de práticas sintonizadas com as necessidades da sociedade ${ }^{\mathrm{iii}}$ e possui uma carga horária total de 2.640 horas/aula ou 176 créditos.

De acordo com a ementa da disciplina Prática de Tradução de Textos Gerais e a ordem de sua apresentação na grade curricular do Curso, busca-se oferecer ao aprendiz de tradução um primeiro contato com a realidade tradutória e a prática profissional. A disciplina contempla aulas teórico-reflexivas sobre a profissão e o tradutor e aulas práticas com a utilização de softwares/ferramentas de auxílio à atividade tradutória. Busca simultaneamente uma aproximação à dicotômica realidade profissional: qualidade final do produto tradutório versus cumprimento de prazo de entrega da tradução.

Com esse intuito é que, já desde o início do Curso, os aprendizes de tradução são apresentados aos softwares/ferramentas disponíveis online para uso nas atividades tradutórias. Esta aproximação visa desenvolver no aprendiz a autorreflexão sobre seu processo tradutório, simultaneamente à apresentação de teorias dos Estudos da Tradução em suas mais diversas perspectivas.

74 As experiências em sala de aula de tradução com o uso de softwares, acompanhados de um relatório posterior que demonstre a reflexão sobre suas práticas tem-se mostrado eficazes no desenvolvimento da competência tradutória dos aprendizes a partir de uma observação individual de seus próprios processos.

Relatam-se aqui as observações e os resultados da experiência com o uso do Translog 2000 já em semestres iniciais e nas primeiras práticas tradutórias no Curso.

\section{As disciplinas de prática no currículo do Curso}

Na composição curricular do Curso de Bacharelado em Tradução da UFPB tem-se uma divisão geral em Conteúdos Básicos Profissionais e Conteúdos Complementares, totalizando uma carga horária de 2.640 horas/aula ao final do Curso. Em Conteúdos Básicos Profissionais distribuem-se disciplinas de línguas estrangeiras modernas, disciplinas teóricas específicas de Estudos da Tradução, disciplinas de metodologia científica e de leitura e produção de textos em língua portuguesa e língua estrangeira. No âmbito das disciplinas de prática, tem-se: Prática de Tradução de Textos Gerais, Prática de Tradução de Textos Comerciais e Técnicos, Prática de Tradução de Textos Jurídicos, Prática de Tradução em Mídia Impressa e Virtual e Prática de Tradução de Textos Literários, que somam 300 h/a, 
distribuídas semestralmente a partir do $2^{\circ}$ semestre do Curso. No $6^{\circ}$ e $7^{\circ}$ semestres, tem-se duas disciplinas de Estágio Supervisionado.

A disciplina de Prática de Tradução em Textos Gerais, de acordo com sua ementa, visa oportunizar a prática de tradução de textos diversos e documentos pessoais com foco no processo tradutório. Em seu Conteúdo Programático incluem-se informações sobre a atividade tradutória e a profissão de tradutor, as condições de trabalho do tradutor, como fazer um orçamento de tradução, quais as entidades existentes para representar o tradutor, quais as habilidades e competências que precisa desenvolver para um bom desempenho da atividade e como se dá o processo tradutório (BRITTO, 2007; ROBINSON, 2002; SAID, 2010, dentre outros).

Para a observação do processo tradutório e visando desenvolver a competência tradutória do aprendiz (HURTADO ALBIR, 2007; ALVES, MAGALHÃES e PAGANO, 2003), a disciplina contempla atividades práticas com uso de softwares, dentre eles o Translog 2000. A inserção deste software na disciplina tem dois objetivos específicos: a autorreflexão sobre o processo tradutório e a aproximação à realidade tradutória do mercado de tradução, na qual o tradutor deverá saber lidar com fatores como a pressão de tempo para o cumprimento da tarefa e a produção de um texto traduzido de qualidade.

Após a consolidação da abordagem processual como campo de pesquisa nos Estudos da Tradução (LIPARINI CAMPOS, 2011, p.2), surgem grupos de pesquisa que estudam aspectos processuais e a competência em tradução (PAGANO, MAGALHÃES e ALVES, 2005) e são desenvolvidas novas ferramentas para a coleta de dados, como o software Translog (ALVES, 1997; LIPARINI CAMPOS, 2010, dentre outros).

O Translog faz a leitura dos movimentos do teclado do computador durante o processo tradutório, gerando um protocolo linear. A partir deste protocolo e da interpretação dos diversos símbolos a ele associados, pode-se verificar, por exemplo, os movimentos de avanço e retrocesso, apagamentos e correções no texto, o uso do mouse, a duração das pausas, etc.

O Quadro 1 a seguir apresenta um fragmento de protocolo linear gerado pelo Translog, de modo a elucidar a sua forma de apresentação. 


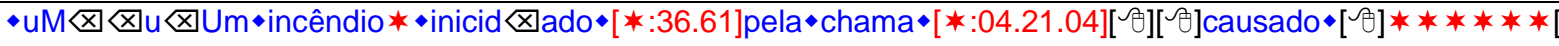

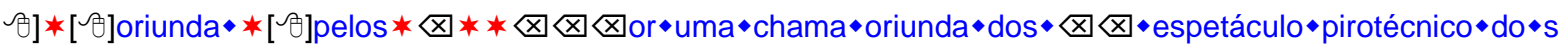

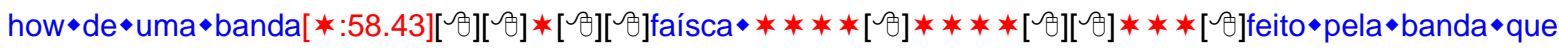
$\bullet$ se apresentava $[*: 35.27]$ alastrou-

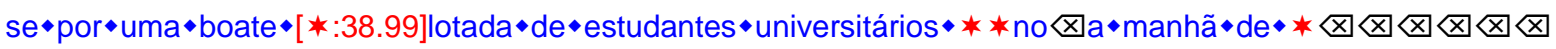

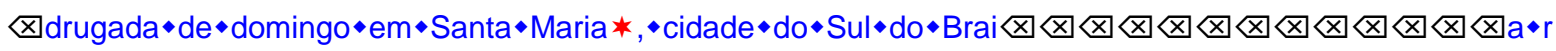

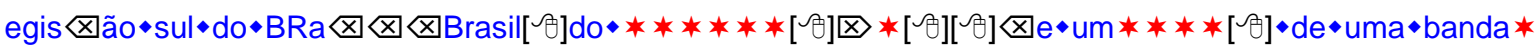

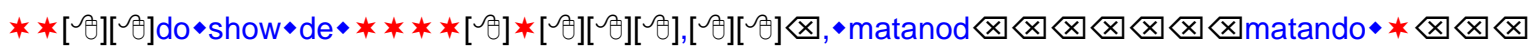

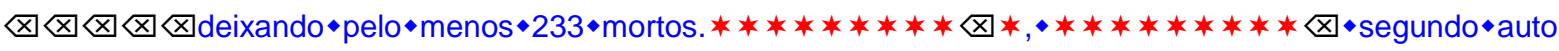

Quadro 1. Fragmento de protocolo linear gerado pelo Translog.

De acordo com os pesquisadores dos processos cognitivos envolvidos na atividade tradutória, é preciso associar a esses protocolos gerados pelo Translog protocolos verbais colhidos pelos tradutores na forma de relatos orais sobre suas ações durante o processo, de modo que se os dados possam ser compreendidos e analisados com maior exatidão. Para as atividades em sala de aula na disciplina de Prática de Tradução de Textos Gerais utilizaram-se apenas os protocolos lineares gerados pelo software, que foram analisados e comentados em 76 relatório final escrito produzido pelos aprendizes.

\section{O desenvolvimento das atividades na disciplina}

A disciplina de Prática de Tradução de Textos Gerais é uma disciplina de 04 créditos, totalizando 60 horas/aula por semestre, distribuídas em dois encontros semanais de 1 hora e 40 minutos de duração. No semestre 2012.2 a professora contou com a colaboração de uma monitora, aluna do Curso que já havia frequentado a disciplina. A professora e a monitora discutiram a forma de condução das aulas, com base nas informações e impressões da aluna. A monitora auxiliou na seleção dos textos a serem traduzidos, sugerindo os temas, traduzindo fragmentos e apontando prováveis dificuldades a serem enfrentadas pelos estudantes.

As atividades de prática de tradução com Translog 2000 foram divididas em quatro aulas de 1 hora e 40 minutos de duração, no período de 05 a 19 de fevereiro de 2013. Os primeiros 50 minutos foram destinados à tradução de textos curtos (entre 286 e 462 palavras) e os 40 minutos restantes para discussão no grande grupo sobre os problemas, as soluções, as ferramentas utilizadas, os sites pesquisados, as observações particulares, etc. De acordo com sugestões da monitora, o formato da aula foi modificado em relação aos semestres anteriores, para que as discussões seguissem imediatamente o momento da tradução e aspectos importantes observados durante a prática não se perdessem. 
O grupo que participou e concluiu as atividades com o Translog era constituído de 13 estudantes, regularmente matriculados no segundo semestre do Curso, ou seja, com ingresso 2012.1, devidamente blocados na grade curricular. Todos os estudantes tem o inglês como língua de trabalho. Para ingresso no Curso de Bacharelado em Tradução os estudantes devem prestar uma prova de conhecimento específico na língua estrangeira escolhida, devendo apresentar o nível A2 de competência de leitura e escrita, de acordo com o Quadro Comum Europeu.

O Translog 2000 foi instalado nos computadores do Laboratório do Curso e houve uma aula de familiarização com o software, na qual os aprendizes poderiam traduzir um texto de livre escolha, retirado da Web.

Foram selecionados para as atividades práticas três gêneros textuais distintos. Inicialmente trabalhou-se com um texto jornalístico de atualidades, tendo-se escolhido o incêndio na Boate Kiss em Santa Maria/RS, ocorrido naquele momento e de conhecimento geral, veiculado por jornais e telejornais nacionais e internacionais ${ }^{\text {iv }}$. O segundo texto escolhido para o projeto correspondeu a um conto (texto literário) - The Princess and the Pea [A princesa e a ervilha] de Hans Christian Andersen, selecionado do site Short Stories do Reino Unido ${ }^{v}$ pela monitora da disciplina. O terceiro e o quarto textos a serem traduzidos corresponderam a duas versões (de diferentes níveis de dificuldade) de um texto técnico, gênero manual, sobre o programa Windows $8^{\text {vi }}$. O objetivo de ter-se trabalhado com duas versões de diferentes níveis de dificuldade, mas de mesmo gênero e temática, foi o de verificar se o conhecimento da terminologia constituía-se como um facilitador do processo, de modo a reduzir, por exemplo, o tempo de busca por equivalentes e, consequentemente, o tempo necessário à tarefa tradutória.

Os aprendizes não tiveram acesso aos textos antes da aula destinada à prática tradutória. Recebiam por e-mail o texto a ser traduzido antes do início da atividade, já posicionados em seus computadores. Quando todos estavam preparados, dava-se início a atividade, que era cronometrada em 50 minutos. Após o tempo destinado à tradução com o software, havia um momento final de fechamento da atividade, no qual se levantavam no grupo as dificuldades, sugestões de tradução, comentavam-se as buscas, as ferramentas utilizadas, etc. 


\section{Os relatos dos aprendizes}

Após os quatro encontros destinados às atividades tradutórias com o software, os aprendizes tinham como tarefa, para obtenção da segunda nota do semestre, a entrega de um relatório sobre o processo tradutório, no qual deveriam apresentar os textos de partida em língua inglesa, os protocolos gerados pelo Translog, os textos traduzidos e os comentários sobre o processo, as dificuldades, as escolhas, as ferramentas utilizadas na busca por soluções tradutórias, as soluções encontradas, as impressões individuais sobre as atividades, sobre os textos selecionados, sobre o uso do software, etc.

Com relação às dificuldades relatadas pelos aprendizes no desenvolvimento das atividades tradutórias pode-se citar:

- a adaptação à estrutura linguística do gênero textual (no caso do texto jornalístico);

- a falta de tempo para revisão;

- o desconhecimento de palavras do texto (com relação ao conto e ao manual);

- a situação de teste, que interferiu no resultado;

- o tema de difícil abordagem (tragédia na boate), devido à influência da emoção;

- a delimitação de tempo para execução da tarefa;

- as deficiências na língua de chegada (português).

Como aspectos facilitadores para o desenvolvimento das atividades tradutórias, os aprendizes citaram, dentre outras coisas:

- o conhecimento prévio do acontecido (no caso do texto jornalístico);

- o conhecimento da maioria das palavras do texto (texto jornalístico);

- a não cobrança do cliente, não existência de pressão prazo/tempo;

- o conhecimento do ambiente Windows, da terminologia e a possibilidade de teste das funções para compreensão e tradução para língua de chegada (manual).

No Quadro 2 a seguir estão relacionadas algumas dificuldades tradutórias específicas, a título de ilustração, bem como a forma de busca por soluções, por parte dos aprendizes, para tais dificuldades. Em suas próprias palavras, relatam o caminho percorrido e suas reflexões sobre o processo. 


\begin{tabular}{|c|c|c|}
\hline $\begin{array}{l}\text { Gênero } \\
\text { textual }\end{array}$ & Dificuldade tradutória & Estratégia encontrada pelo tradutor \\
\hline \multirow[t]{3}{*}{$\begin{array}{l}\text { Texto } \\
\text { jornalístico }\end{array}$} & $\begin{array}{l}\text { sweep through } \quad-\quad \text { Expressão } \\
\text { desconhecida. }\end{array}$ & $\begin{array}{l}\text { Colei parágrafo para contextualização no Google } \\
\text { Translate. Resultado tradução literal: "varreu”. } \\
\text { Busquei no Linguee. Resultados também não precisos, } \\
\text { mas uma opção ajudou a chegar à tradução final: } \\
\text { "atravessar". Não era a palavra que procurava, mas } \\
\text { deixei de lado a expressão em inglês e pensei qual } \\
\text { seria a palavra, em português, usada para o fogo que se } \\
\text { espalha. Então lembrei de "alastrar". }\end{array}$ \\
\hline & $\begin{array}{l}\text { bodies - Estranhei vocábulo escolhido } \\
\text { no original. }\end{array}$ & $\begin{array}{l}\text { Em português, usamos a palavra "corpos" para } \\
\text { pessoas que já morreram. Não fazia sentido transportar } \\
\text { pessoas que já morreram para serem tratadas em } \\
\text { hospitais. Optei por palavra que se encaixava melhor } \\
\text { no contexto: "vítimas" pode se referir tanto a vítimas } \\
\text { fatais quanto a não fatais. }\end{array}$ \\
\hline & $\begin{array}{l}\text { push through - Prendi-me à literaridade } \\
\text { da expressão e não pensei, } \\
\text { imediatamente, na melhor solução em } \\
\text { português. }\end{array}$ & $\begin{array}{l}\text { Imaginei a cena descrita e vi que "forçar a passagem" } \\
\text { soava mais natural em português. }\end{array}$ \\
\hline \multirow[t]{2}{*}{ Conto } & $\begin{array}{l}\text { old king - Gênero histórias infantis - } \\
\text { muitos adjetivos para descrever } \\
\text { personagens. Soava negativo traduzir por } \\
\text { "rei velho". }\end{array}$ & $\begin{array}{l}\text { Digitei "rei pai" e, na revisão, deixei "rei”. Velho rei } \\
\text { não soaria negativo e seria a tradução mais condizente } \\
\text { com gênero "histórias infantis". }\end{array}$ \\
\hline & $\begin{array}{l}\text { laid a pea on the bottom - Primeira } \\
\text { solução "fundo". }\end{array}$ & $\begin{array}{l}\text { Na revisão percebi que "pôs uma ervilha no fundo" } \\
\text { não soava bem em português. Troquei por "tirou todos } \\
\text { os lençóis que cobriam a cama e pôs uma ervilha lá } \\
\text { embaixo". }\end{array}$ \\
\hline \multirow[t]{2}{*}{ Manual } & $\begin{array}{l}\text { seach charm - Só conhecia "charm" - } \\
\text { charme, atrativo ou amuleto. Nenhuma } \\
\text { cabia no contexto. }\end{array}$ & $\begin{array}{l}\text { Pesquisei no dicionário Wordnik e no Google } \\
\text { Translate para encontrar outra acepção. Não obtive } \\
\text { resultados satisfatórios. Optei por "atalho", mas não } \\
\text { fiquei satisfeita. Deixei "atalho" como solução } \\
\text { temporária e prossegui com a tradução. Na metade do } \\
\text { texto, o termo apareceu novamente. Busquei o site do } \\
\text { próprio Windows para ver qual a tradução já usada. } \\
\text { Taduzem "charm" como "botão”, voltei e alterei. }\end{array}$ \\
\hline & $\begin{array}{l}\text { freshen up your } P C \text { - A tradução literal } \\
\text { não fazia sentido. Uma instrução que } \\
\text { dissesse "refresque seu } P C \text { " poderia dar } \\
\text { margem a interpretações erradas. }\end{array}$ & $\begin{array}{l}\text { Primeiro traduzi como "faça uma limpeza", depois fiz } \\
\text { uma leitura do parágrafo completo e, pelo contexto, } \\
\text { preferi traduzir por "Otimize o desempenho de seu } \\
P C \text { ", pois era isso que, no fim das contas, o texto } \\
\text { dizia. }\end{array}$ \\
\hline
\end{tabular}

Quadro 2. Dificuldades tradutórias específicas relatadas pelos aprendizes.

Dentre as ferramentas, sites de busca, dicionários online, corpora online, etc. utilizados pelos aprendizes durante o processo tradutório, citam-se:

- Google Traslate $\rightarrow$ http://translate.google.com.br

- Dicionário Priberam (português) $\rightarrow$ http://www.priberam.pt/DLPO/

- Dicionário Wordnik (inglês) $\rightarrow$ http://www.wordnik.com

- Dicionário de sinônimos $\rightarrow$ http://www.sinonimos.com.br

- Dicionário Cambridge $\rightarrow$ http://dictionary.cambridge.org/us/ 
- Word Reference $\rightarrow$ www.wordreference.com

- Corpus paralelo COMPARA $\rightarrow$ http://193.136.2.104/COMPARA/index.php

- Corpus paralelo Linguee $\rightarrow$ http://www.linguee.com/

- Busca de glossários do Proz $\rightarrow$ http://www.proz.com/search/

- Google do Reino Unido $\rightarrow$ www.google.co.uk

- Leitura de outras notícias sobre o mesmo tema.

\section{As conclusões dos aprendizes quanto às atividades tradutórias}

Após os relatos dos aprendizes sobre as dificuldades com os textos a serem traduzidos nas atividades em sala de aula e as dificuldades específicas no processo tradutório, apresentam-se a seguir algumas conclusões a que chegaram com relação ao resultado das atividades desenvolvidas em sala de aula com o uso do software Translog:

- as decisões tradutórias baseadas apenas no conhecimento prévio da língua de partida (inglês) provocam erro;

- a pressão de tempo/prazo, os descuidos e a falta de revisão comprometem a tradução;

- a observação do processo faz reconhecer as estratégias tradutórias;

- há interferência da pressão tempo/prazo, por isso a necessidade de desenvolver estratégias para aumentar velocidade tradutória;

- o uso do Translog interfere no processo, mas é preciso reconhecer que as condições da tradução nem sempre são ideais para o tradutor e é preciso aprender a lidar com essas adversidades na profissão futura;

- a experiência com o uso do Translog trouxe aprendizado e permitiu questionamentos enriquecedores à vida profissional e acadêmica, motivando a aperfeiçoar métodos de tradução.

Os relatos apresentam parte das reflexões individuais sobre as experiências iniciais na prática tradutória. Neste sentido, entende-se que a disciplina de Prática de Tradução de Textos Gerais, inserida na organização curricular do Curso de Bacharelado em Tradução, está de acordo com abordagens pedagógicas atuais, que entendem que a apreensão pode ser otimizada por um processo reflexivo por parte do aprendiz e através da vivência de experiências concretas, que simulam contextos profissionais reais. Em consonância com os pressupostos 
básicos do construtivismo, é oportunizada aos aprendizes de tradução a participação ativa em sua aprendizagem.

\section{Considerações finais}

$\mathrm{Na}$ docência em cursos de formação de tradutores observa-se que, em práticas tradutórias iniciais, os aprendizes privilegiam uma equivalência no nível da palavra. Este fato conduz o docente a buscar novas formas para incrementar o ensino de tradução no sentido de uma reflexão sobre o fazer tradutório. Tomando como ponto de partida as próprias dificuldades dos aprendizes e as soluções por eles encontradas, busca-se apontar outros caminhos no sentido da qualificação do processo tradutório.

Sabe-se que a competência tradutória corresponde a uma combinação de capacidades, habilidades e conhecimentos numa dada situação comunicativa, que inclui a situação da comunicação intermediada pela tradução (LEIPNITZ, 2010, p.61). Cada uma das competências que constituem a competência tradutória abrange, por um lado, capacidades implícitas e, por outro lado, conhecimento explícito (SNELL-HORNBY et al., 2006, p.341).

A competência tradutória implícita corresponderia à capacidade de buscar informações relevantes no texto de partida e adaptá-las, de acordo com as necessidades e exigências, no texto de chegada. Conhecimentos explícitos na competência tradutória correspondem a conceitos, métodos e estratégias de tradução. As estratégias correspondem a reconhecer e solucionar problemas tradutórios, mas também a formas de valorização das traduções.

Os Estudos de Tradução, ao distinguirem competência linguística de competência tradutória, identificam um continuum entre experiente e novato, considerando a competência em tradução um conhecimento especializado, integrado por um conjunto de conhecimentos e habilidades, que pode ser facilitado por um processo de ensino-aprendizagem - a didática da tradução (PAGANO, MAGALHÃES e ALVES, 2005).

A competência tradutória requer, para além de conhecimentos linguísticos, textuais, temáticos, culturais, de documentação e capacidade de transferência, também o componente estratégico (HURTADO ALBIR, 2005, p.23). São as estratégias e as habilidades individuais que transformam um aprendiz num profissional tradutor, e essas habilidades podem ser incrementadas pela didática da tradução.

O desenvolvimento da competência tradutória corresponde a um continuum entre o natural e o construído, entre o conhecimento do aprendiz e o do profissional tradutor. Neste sentido, o feedback tem papel essencial no desenvolvimento de tal competência e sua 
aquisição corresponde a um processo de automação gradual e de reflexão crítica do aprendiz sobre as suas próprias intuições (LEIPNITZ, 2010, p.82).

As atividades tradutórias desenvolvidas durante o semestre 2012.2 na disciplina de Prática de Tradução de Textos Gerais com o uso do software Translog 2000 mostraram-se não apenas produtivas com relação aos objetivos propostos pela disciplina, mas também e principalmente no sentido da formação geral do futuro tradutor, no desenvolvimento da competência tradutória dos aprendizes por meio da reflexão sobre a prática.

Apesar de não terem sido analisados especificamente os processos cognitivos da forma como são propostos pelos pesquisadores que fazem uso do Translog e de seus protocolos lineares, ou seja, com a anexação de protocolos retrospectivos produzidos pelos tradutores, gravados, transcritos e salvos em corpus para posterior utilização (ALVES, 2003), as observações dos aprendizes de tradução registradas em seus relatórios finais demonstraram reflexão sobre os seus processos tradutórios e um trabalho cuidadoso de verificação das formas como buscaram soluções aos problemas encontrados em sua atividade tradutória. Ao analisarem seus protocolos lineares demonstraram observação cuidadosa sobre os diferentes 82 registros nos protocolos. A proposta do relatório final fez com que observassem e registrassem seus processos de busca por soluções, os caminhos percorridos para encontrá-las, bem como as reflexões a cerca de decisões tradutórias finais.

$\mathrm{O}$ fato de terem sido testados igualmente com relação ao tempo destinado ao trabalho fez com que se deparassem com uma primeira experiência de cobrança de tempo/prazo para realização de uma tarefa tradutória. Essa experiência se faz importante, pois se constitui em uma realidade com a qual precisão lidar em suas vidas como profissionais. Apesar de sabermos que a qualidade de uma tradução não deve ser comprometida pela exigência de tempo de conclusão, ou seja, que a qualidade do texto traduzido deve sempre estar acima da exigência de prazo, estamos cientes de que esta é uma realidade do mercado com a qual irão se deparar no exercício de sua profissão. Dessa forma, acreditamos também na contribuição desse aspecto em suas reflexões sobre o processo tradutório, no intuito de buscarem estratégias que os capacitem a uma qualificação do trabalho simultânea a um menor tempo de execução da tarefa.

Claro está que a proposta dessas atividades desenvolvidas em sala de aula nesse semestre deverá ser retomada em semestres seguintes, sendo então considerados outros aspectos dessa tradução. Essa retomada do trabalho deverá oportunizar aos aprendizes a revisão das traduções efetuadas, o retorno a suas anotações a respeito das buscas, escolhas e 
soluções tradutórias e uma nova reflexão sobre o processo tradutório, de modo a compará-lo com o seu desenvolvimento ao longo do Curso e da verificação da efetividade das atividades propostas em suas práticas, bem como das teorias abordadas sobre o desenvolvimento da competência tradutória.

É a partir da aprendizagem reflexiva que se pretende uma aprendizagem efetiva da tradução e o desenvolvimento permanente da competência tradutória, pautado também na construção coletiva do conhecimento por meio do compartilhamento de experiências.

\section{REFERÊNCIAS BIBLIOGRÁFICAS}

ALVES, F. A formação de tradutores a partir de uma abordagem cognitiva: reflexões de um projeto de ensino. TradTerm, 4/2, 1997. p.19-40. Disponível em http://myrtus.uspnet.usp.br/tradterm/site/images/revistas/v04n2/v04n2a04.pdf Acesso em: 24 jan. 2013.

Tradução, cognição e contextualização: triangulando a interface processo-produto no desempenho de tradutores novatos. DELTA, v.19, n. esp. São Paulo, 2003. Disponível em http://www.scielo.br/scielo.php?pid=S0102-44502003000300006\&script=sci_arttext Acesso em: 24 jan. 2013.

ALVES, Fábio; MAGALHÃES, Célia; PAGANO, Adriana. Traduzir com autonomia: estratégias para o tradutor em formação. São Paulo: Contexto, 2003.

BRITTO, P. H. As condições de trabalho do tradutor. Cadernos de Tradução, v.1, n.19, 2007. p.193-204. Disponível em

https://periodicos.ufsc.br/index.php/traducao/article/view/6998/6483 Acesso em: 11 dez. 2012.

HURTADO ALBIR, Amparo. Traducción y Traductología. Introducción a la traductología. 3.ed. Madri: Cátedra, 2007.

A aquisição da competência tradutória: aspectos teóricos e didáticos. In: PAGANO, Adriana; MAGALHÃES, Célia; ALVES, Fábio. Competência em Tradução: Cognição e Discurso. Belo Horizonte: Editora da UFMG, 2005. p.19-57.

LEIPNITZ, Luciane. Da descrição dos usos da língua ao ensino da tradução: combinatórias textuais em língua alemã e implementação do ambiente Virtualern. Porto Alegre, 2010. Tese (Doutorado em Letras) - Programa de Pós-Graduação em Letras Universidade Federal do Rio Grande do Sul. Disponível em http://www.ufrgs.br/termisul/biblioteca/teses/tese_PPG-Letras_2010_LEIPNITZ.pdf Acesso em: 24 jan. 2013.

LIPARINI CAMPOS, T. A abordagem processual nos estudos da tradução. Anais do SILEL. Volume 2, Número 2. Uberlândia: EDUFU, 2011. Disponível em http://www.ileel.ufu.br/anaisdosilel/pt/arquivos/silel2011/1948.pdf Acesso em fevereiro de 2013. 
O efeito do uso de um sistema de memória de tradução e da pressão de tempo no processo cognitivo de tradutores profissionais. Belo Horizonte, 2010. Tese (Doutorado em Linguística Aplicada) - Faculdade de Letras da Universidade Federal de Minas Gerais/PosLin.

PAGANO, A.; MAGAlHÃES, C.; ALVES, F. Competência em tradução. Cognição e discurso. Belo Horizonte: UFMG, 2005.

ROBINSON, Douglas. Construindo o tradutor. Tradução de Jussara Simões. Bauru, SP: EDUSC, 2002.

SAID, F. M. Fidus Interpretes: A prática da tradução profissional. São Paulo: Edição do autor, 2010.

SNELL-HORNBY, Mary; HÖNIG, Hans G.; KUßMAUL, Paul; SCHMITT, Peter A. (Hrsg.). Handbuch Translation. 2.verbesserte Auflage. Tübingen: Stauffenburg Verlag, 2006.

\begin{tabular}{lllll}
\hline i Currículo & Lattes. & Luciane & Leipnitz.
\end{tabular}
http://buscatextual.cnpq.br/buscatextual/visualizacv.do?id=K4736805E0

ii Para maiores informações sobre o software, consulte http://www.translog.dk/default.asp?id=20.

iii Para maiores informações sobre o Curso, consulte http://www.cchla.ufpb.br/ctrad/index.php/o-curso.

iv Disponível em http://www.nytimes.com/2013/01/28/world/americas/brazil-nightclub-fire.html.

84 v Disponível em http://www.short-stories.co.uk/.

vi Disponível em http://windows.microsoft.com/en-us/windows8. 